Ciência Florestal, Santa Maria, v. 27, n. 1, p. 339-340, jan.-mar., 2017

ISSN 1980-5098

\title{
DIAGNÓSTICO DAS FLORESTAS PLANTADAS NA BACIA HIDROGRÁFICA DO RIO PARDO - RS
}

\author{
DIAGNOSIS OF THE FORESTS PLANTED IN RIVER BASIN OF ‘PARDO’ RIVER, \\ RIO GRANDE DO SUL STATE
}

\author{
Jorge Antonio de Farias ${ }^{1}$ Paulo Renato Schneider ${ }^{2}$ Leonardo Job Biali ${ }^{3}$
}

\begin{abstract}
RESUMO
O presente estudo visa fazer um diagnóstico das florestas plantadas na Bacia Hidrográfica do Rio Pardo RS, contemplando a caracterização das propriedades, dos florestamentos, e a disponibilidade e o consumo de madeira na região. A área de abrangência do estudo fica na região central do Rio Grande do Sul, cuja economia principal é a fumicultura, abrangendo 13 municípios que compõem a área de atuação do Comitê de Gerenciamento da Bacia Hidrográfica do Rio Pardo. A coleta dos dados foi conduzida no decorrer do ano de 2008. Para a determinação do tamanho da amostra, foi feita uma amostragem com probabilidade proporcional ao tamanho, sendo que o critério de distribuição das unidades amostrais levou em consideração o número de árvores por município e, dentro dos municípios, o número de árvores por classe de tamanho de propriedade. $\mathrm{O}$ método de amostragem utilizado no inventário florestal foi o de Prodan, além de ter sido feitas entrevistas com os produtores. A região é caracterizada por pequenos produtores rurais, e $61,4 \%$ da lenha utilizada na cura das folhas de tabaco é adquirida de terceiros, além disso, a maioria dos florestamentos possui espaçamentos reduzidos $\left(2,26 \mathrm{~m}^{2} /\right.$ planta) e baixos índices de sobrevivência, na ordem 34,4\% após 7 anos do plantio. O estoque atual de madeira é de $2.781 .069 \mathrm{~m}^{3}$, o que garante um abastecimento para apenas 3,5 anos. Os dados levantados permitem constatar que os recursos necessários para investir na autossuficiência de lenha para a fumicultura, são de R $\$ 12.250 .000,00$, que poderiam ser alocados anualmente, durante sete anos, equivalente à rotação em talhadia simples, resultando em uma área de $80 \mathrm{ha} /$ ano/município.
\end{abstract}

Palavras-chave: agricultura familiar; inventário florestal; método de Prodan; economia florestal.

\begin{abstract}
The present study aims to make a diagnosis of the forests planted in the basin of 'Pardo' river (Rio Pardo), in RS state, by contemplating the characterization of properties, of forestations, and of the availability and consumption of wood in the region. The area of reach of the study is in the central region of Rio Grande do Sul state, which main economy is the tobacco crop, enclosing 13 cities that compose the performance area of the Management Committee of Rio Pardo Hydrographic Basin. The data collect were conducted during year 2008. In order to determine the size of the sample, it was made a sampling with its probability proportional to the size, where the criterion of the sample unity distribution took in consideration the numbers of trees per city and, inside the cities, the number of trees per class of property size. The sampling method utilized on the forest inventory was by Prodan, in addition to interviews taken with the producers.
\end{abstract}

1 Engenheiro Florestal, Dr., Professor Adjunto do Departamento de Ciências Florestais, Centro de Ciências Rurais, Universidade Federal de Santa Maria, Av. Roraima, 1000, CEP 97105-900, Santa Maria (RS), Brasil. fariasufsm@gmail.com

2 Engenheiro Florestal, Dr., Professor Titular do Departamento de Ciências Florestais, Centro de Ciências Rurais, Universidade Federal de Santa Maria, Av. Roraima, 1000, CEP 97105-900, Santa Maria (RS), Brasil. paulors@smail.ufsm.br

3 Engenheiro Florestal, Dr., Programa de Pós-graduação em Engenharia Florestal, Centro de Ciências Rurais, Universidade Federal de Santa Maria, Av. Roraima, 1000, CEP 97105-900, Santa Maria (RS), Brasil. ljbiali@gmail.com

Recebido para publicação em 20/12/2011 e aceito em 1/06/2015

Ci. Fl., v. 27, n. 1, jan.-mar., 2017 
The region is characterized by small agricultural producers, and $61.4 \%$ of the firewood used in the cure of tobacco leaves is acquired from others, moreover, the majority of the forestation possess reduced spacing $\left(2.26 \mathrm{~m}^{2} / \mathrm{plant}\right)$ and low survival indices, in order of the $34.4 \%$ after 7 years of the plantation. The wooden current supply is of $2,781.069 \mathrm{~m}^{3}$, what guarantees a supplying for only 3.5 years. The collected data allow to evidence that the resources necessary to invest in the self-sufficiency of firewood for the crop tobacco, are of $\mathrm{R} \$ 12,250,000,00$, that could be placed annually, during seven years, equivalent the rotation in simple coppice, resulting in an area of $80 \mathrm{ha} /$ year/city.

Keywords: family farming; forest inventory; prodan method; forest economy.

\section{INTRODUÇÃO}

O papel da floresta vai muito além de produção de produtos madeiráveis, a sua importância não é percebida pela imensa maioria da população, uma vez que seus benefícios podem ser tanto de ordem econômica como social, principalmente pelos benefícios ambientais que proporciona. A cobertura florestal protege o solo, os mananciais de água e a fauna, evita enchentes, captura dióxido de carbono, aumenta a vida útil de reservatórios hídricos, e também pode ser uma fonte fornecedora de alimentos, remédios, materiais para construção e renda. (FERREIRA e GALVÃO, 2000).

Em 1983, o inventário florestal do Rio Grande do Sul constatou a seguinte situação florestal: uma área projetada de 174.396 ha de florestas plantadas, vinculadas ao IBDF - Instituto Brasileiro de Desenvolvimento Florestal. Deste total, 95.404 ha de Pinus spp., 22.629 ha de Eucalyptus spp., 8.850 ha de Araucaria angustifolia e 32.387 ha de Acacia mearnsii (IBDF, 1983). Estes dados foram apurados para as florestas com algum tipo de vínculo com o IBDF, deixando de evidenciar significativas áreas florestais plantadas com recursos próprios e não vinculadas ao órgão federal. Entretanto, os dados acima foram largamente divulgados e trabalhados como se esta fosse a realidade de todo o estado do Rio Grande do Sul.

Entretanto, o inventário florestal realizado em 2003, encontrou uma área de florestamentos de 274.748 ha de florestas plantadas, sendo 111.525 ha de eucalipto, 153.583 ha de pinus e 9.640 ha de acácianegra (SEMA, 2003).

Ao se compararem os dados dos dois inventários, chama a atenção a discrepância dos dados, especialmente em relação à área com acácia-negra, quando é notória a informação de que a área de acácianegra é muito maior do que consta no inventário, corroborando as informações divulgadas pelo setor de base florestal, o que coloca em dúvida a credibilidade do trabalho. Conforme a literatura no final da década de 1990, a expansão da base florestal desta espécie oscilava entre 15.000 e 20.000 ha/ano (TONIETTO e STEIN, 1997) atingindo um total de 160.000 ha de florestas na metade da década de 2000 (MÜLLER, 2006).

Estas informações, acerca da cobertura florestal, são relevantes para o contexto do estudo, uma vez que a região do Vale do Rio Pardo, colonizada principalmente por alemães, caracterizou-se por estabelecer um modelo de ocupação fundiária, baseado nas pequenas propriedades rurais, no plantio do tabaco, na conservação de florestas, pelo consumo de lenha para cura das folhas de tabaco e, também, pela topografia que dificultava a implantação de lavouras mais extensivas (ETGES, 2001).

Dessa forma, a atividade florestal na região do Vale do Rio Pardo sempre teve uma característica econômica relevante, mesmo não sendo a atividade fim, basicamente, porque a lenha constitui-se em insumo importante no custo de produção da cultura do tabaco (FARIAS e BIANCO, 1999).

Talvez, em função desta importância, criou-se na região um conceito de que a atividade florestal resume-se à produção de lenha e, principalmente, de que as florestas de rápido crescimento, especialmente o gênero Eucalyptus, teriam melhor uso para essa finalidade (FREY e WITTMANN, 2007).

O objetivo deste estudo é diagnosticar a situação das florestas plantadas na Bacia Hidrográfica do Rio Pardo - RS, através da caracterização do perfil das propriedades e dos florestamentos nestas inseridas, além de identificar a disponibilidade e o consumo regional de madeira para energia pela fumicultura, visando analisar as perspectivas futuras. 


\section{MATERIAL E MÉTODOS}

O estudo foi desenvolvido no Rio Grande do Sul, abrangendo 13 municípios que compõem a área de atuação do Comitê de Gerenciamento da Bacia Hidrográfica do Rio Pardo. A Bacia Hidrográfica do Rio Pardo, localizada na região central do Estado do Rio Grande do Sul.

Segundo Andrae (1978), a região em estudo pertence à região fisiográfica definida como encosta inferior do nordeste, com altitudes que variam de 50 metros até 600 metros acima do nível médio do mar.

A coleta dos dados foi conduzida no decorrer do ano de 2008. O modelo de amostragem utilizado levou em consideração que o objeto a ser inventariado não é a propriedade rural, mas a área de florestas plantadas. Assim, para a determinação do tamanho da amostra, ou seja, do número de propriedades cobertas pelo inventário, foi utilizado o processo denominado de amostragem com probabilidade proporcional ao tamanho (PPT), no presente estudo, o tamanho das áreas com florestas plantadas. Está metodologia é recomendada para inventários de florestas plantadas de grandes dimensões, devido à distribuição das unidades ser proporcional ao tamanho dos estratos, resultando em uma autoponderação do erro de amostragem (PÉLLICO NETTO, 1996).

Dessa forma, o processo de amostragem do inventário florestal considerou o número de árvores plantadas por produtor rural, sendo que o critério de distribuição das unidades amostrais levou em consideração o número de árvores por município e dentro dos municípios, o número de árvores por classe de tamanho de propriedade.

Para o cálculo do número de propriedades por município (unidades primárias) amostradas, bem como o número de propriedades por classe fundiária (unidades secundárias) definiu-se uma variável $Z_{\mathrm{i}}$, que, segundo Péllico Netto (1996), representa a proporção referente ao tamanho da amostra das unidades primárias em relação ao todo da área dentro de um estrato. Assim tem-se:

$$
Z_{i}=\frac{M_{i}}{M}=\frac{A_{i}}{A}
$$

Em que: $\mathrm{M}_{\mathrm{i}}=$ Número de elementos dentro de cada unidade primária; $\mathrm{M}=$ Número total de elementos na área de um estrato; $\mathrm{A}_{\mathrm{i}}=$ Área de cada unidade primária; $\mathrm{A}$ = Área do estrato considerado.

Anualmente, os agricultores associados à Associação dos Fumicultores do Brasil (AFUBRA) informam a área reflorestada de sua propriedade, bem como o consumo de lenha, entre outras informações. Dessa forma, a metodologia enfocou a alocação de amostragem proporcional ao número de árvores plantadas por "classe fundiária". A priori, foram estabelecidas 130 "unidades secundárias" (propriedades), selecionadas com probabilidade proporcional ao número de árvores plantadas, pois se estima que, a partir de 130 unidades amostrais, o aumento do número de amostras não interfere no coeficiente de variação, não melhorando a estimativa. A Tabela 1 apresenta o resultado da amostragem proporcional, levando em consideração o peso do número de hectares reflorestados para cada classe fundiária, distribuídas proporcionalmente por município.

Cada unidade secundária (propriedade rural), após a definição da proporcionalidade, foi selecionada através do processo de amostragem inteiramente aleatório simples, conforme a classe fundiária indicada pelo processo PPT (unidades primárias), no banco de dados da Afubra. Dessa forma, é possível observar na Tabela 1, que ocorre maior concentração de unidades primárias nas classes fundiárias entre 5,1 a 30 ha, devido ao fato destas concentrarem o maior número de árvores plantadas, consequentemente, maior área.

Os diferentes regimes de manejo adotados (talhadia, alto fuste, etc.) nos povoamentos de Eucalyptus spp., acarretam em grande heterogeneidade, isto pode ocorrer também devido a falhas na implantação o que resulta em florestas desuniformes (SILVA, 2007). Para abranger esta diferença, foi realizada uma pósestratificação na população.

Portanto, todas as formações florestais plantadas sofreram amostragem e, em cada uma destas formações, foram alocadas 3 parcelas, resultando em um número de 1.191 unidades amostrais, sendo possível amostrar florestas equiâneas e inequiâneas da mesma espécie e florestas com sistemas de manejo diferentes, sendo que muitas destas situações ocorriam na mesma propriedade. 
O método de amostragem utilizado no inventário florestal foi o de Prodan, também denominado Método das Seis Árvores. Este método consiste na medição das seis árvores mais próximas de um ponto amostral (PÉLLICO NETTO e BRENA, 1997).

Os diâmetros foram coletados com o auxílio de uma suta de $60 \mathrm{~cm}$ e as alturas foram obtidas através do uso da prancheta dendrométrica. O erro de amostragem foi fixado em no máximo $10 \%$, e a estimativa do volume para uma probabilidade de $95 \%$.

TABELA 1: Distribuição das unidades amostrais primárias de acordo com amostragem proporcional ao número de mudas de Eucalyptus spp. distribuídas por município e por classe fundiária.

TABLE 1: Distribution of the primary sample units with proportional sampling to the number of seedlings of Eucalyptus spp. distributed by each city and by the agrarian class.

\begin{tabular}{lccccccccc}
\hline \multirow{2}{*}{\multicolumn{1}{c}{ Município }} & \multicolumn{1}{c}{ Classe fundiária } & Total \\
\cline { 2 - 8 } & $01-05$ & $5,1-10$ & $10,1-15$ & $15,1-20$ & $20,1-30$ & $30,1-40$ & $40,1-50$ & $>50,1$ & \\
\hline Barros Cassal & 0 & 3 & 3 & 2 & 2 & 1 & 0 & 0 & 11 \\
Boqueirão do Leão & 0 & 1 & 2 & 2 & 2 & 1 & 1 & 1 & 10 \\
Candelária & 1 & 3 & 2 & 2 & 2 & 0 & 0 & 0 & 11 \\
Gramado Xavier & 0 & 1 & 1 & 1 & 1 & 1 & 0 & 1 & 7 \\
Herveiras & 0 & 1 & 1 & 1 & 1 & 0 & 0 & 0 & 5 \\
Lagoão & 0 & 1 & 0 & 0 & 0 & 0 & 0 & 0 & 2 \\
Passa Sete & 0 & 1 & 2 & 1 & 2 & 1 & 0 & 0 & 9 \\
Rio Pardo & 0 & 1 & 0 & 0 & 0 & 0 & 0 & 0 & 2 \\
Santa Cruz do Sul & 1 & 5 & 5 & 4 & 3 & 1 & 0 & 0 & 18 \\
Sinimbu & 0 & 1 & 2 & 2 & 3 & 1 & 0 & 1 & 10 \\
Vale do Sol & 1 & 4 & 4 & 3 & 3 & 2 & 1 & 0 & 17 \\
Venâncio Aires & 2 & 8 & 5 & 2 & 2 & 1 & 0 & 0 & 19 \\
Vera Cruz & 1 & 2 & 2 & 1 & 1 & 0 & 0 & 0 & 8 \\
\hline \multicolumn{1}{c}{ Total } & 7 & 33 & 31 & 21 & 22 & 8 & 3 & 4 & 130 \\
\hline
\end{tabular}

\section{RESULTADOS E DISCUSSÃO}

\section{Características das propriedades rurais}

Os dados contidos na Tabela 2 reiteram as informações de que a região de estudo tem um perfil de propriedades minifundiárias e se reportam aos agricultores que cultivam tabaco.

Muito se tem falado da importância social da fumicultura. Várias entidades de classe, que defendem o agricultor que cultiva tabaco, têm dito que há necessidade de distinguir o tabagismo (hábito de fumar) do cultivo de tabaco. $\mathrm{O}$ argumento fundamental é a condição de sobrevivência que as pequenas famílias rurais têm com o cultivo do tabaco, por possibilitar o cultivo em pequenas áreas e sem mecanização, torna-se a única opção para fixação destes produtores no campo (VOGT, 2000). Conforme Goetze e Thomé (2004), a cultura do tabaco é a principal atividade econômica do Vale do Rio Pardo.

Na Tabela 2 é possível perceber que a fumicultura é fundamental não só para os pequenos produtores, mas também para uma parcela significativa de famílias rurais que não possuem terras.

Estima-se que a fumicultura garanta renda para 77.587 famílias, que não são proprietárias das áreas que plantam tabaco. Caso se acrescentem, nesse cálculo, as famílias com até 10 ha, condição fundiária de difícil diversificação e alternativa de renda, tem-se um total de $73,47 \%$ das famílias, o que corresponde a 132.628 famílias. 
No início da colonização, as propriedades eram distribuídas aos imigrantes em lotes de 48 ha e depois 24 ha (ETGES, 1989). Como atualmente a quarta geração dos primeiros imigrantes assumiu as propriedades, as áreas sofreram sucessivas divisões, resultando em um número muito grande de pequenas propriedades com um número muito grande de pequenos proprietários.

A ocupação do solo pelos agricultores que cultivam tabaco é bastante diversificada. Mesmo com uma área média de 18,5 ha, e com, 30,5\% dos produtores situando-se entre os que possuem até 10 ha, e com outros $43,0 \%$ de não proprietários, a região produz uma pauta de produtos agrícolas diversificados.

A ocupação do solo nestas pequenas propriedades dá-se, conforme a Tabela 3, ressaltando a significativa cobertura florestal, que totaliza $25,7 \%$. Estes dados são provenientes do banco de dados da Afubra e representam dados médios de uma população de aproximadamente 141.470 famílias, formadas por diferentes etnias, tipos de solo, relevo e clima, contemplando os 3 estados da região sul do Brasil.

Também existe outro aspecto comum à pequena propriedade: é a área destinada à pastagem, em torno de $21,0 \%$. É sabido que a pecuária de leite é outra atividade com perfil característico de pequenas propriedades rurais, nem tanto como fonte de renda, mas principalmente para a autossuficiência de leite e outras fontes de proteína para as famílias rurais.

Em relação ao uso do eucalipto na pequena propriedade é importante salientar que este gênero, dentre as espécies de rápido crescimento, é o que melhor se adapta ao perfil da pequena propriedade. Isso porque o eucalipto caracteriza-se por ser uma espécie versátil e de uso múltiplo, podendo abastecer plenamente a propriedade rural em lenha, madeira para cercas, para reforma e construção de benfeitorias, e, claro, como fonte de lenha para as estufas (unidades de cura).

TABELA 2: Estrutura fundiária dos fumicultores na área de abrangência da Bacia Hidrográfica do Rio Pardo.

TABLE 2: Agrarian structure of tobacco growers in the range area of 'Pardo' river basin.

\begin{tabular}{ccccc}
\hline Classe & Tamanho das propriedades (ha) & Número (\%) & $\mathrm{N}^{\circ}$ de famílias & Famílias/classe (\%) \\
\hline 1 & Arrendatários & & 9.321 & 42,98 \\
2 & 00,1 a 10,0 & 24,7 & 6.613 & 30,49 \\
3 & 10,1 a 15,0 & 18,8 & 2.377 & 10,96 \\
4 & 15,1 a 20,0 & 15,6 & 1.407 & 6,49 \\
5 & 20,1 a 30,0 & 19,0 & 1.232 & 5,68 \\
6 & 30,1 a 40,0 & 8,6 & 0.396 & 1,83 \\
7 & 40,1 a 50,0 & 4,3 & 0.151 & 0,70 \\
8 & $>50,1$ & 9,1 & 0.191 & 0,88 \\
\hline
\end{tabular}

Fonte: Afubra (2008).

TABELA 3: Perfil de uso do solo nas propriedades dos fumicultores na região sul do Brasil. TABLE 3: Profile of use of the ground in the properties of tobacco growers in southern Brazil.

\begin{tabular}{lcc}
\hline \multicolumn{1}{c}{ Atividades } & $\%$ & Vale do Rio Pardo (ha) \\
\hline Açudes & 0,9 & 1.399 \\
Área em Descanso & 10,6 & 16.895 \\
Lavouras & 41,9 & 66.979 \\
Florestamento & 10,1 & 16.195 \\
Vegetação Nativa & 15,6 & 24.857 \\
Remanescente & 21,0 & 33.527 \\
Pastagens & 100,0 & 159.852 \\
\hline \multicolumn{2}{c}{ Total } &
\end{tabular}

Fonte: Afubra (2008). 
$\mathrm{Na}$ área de estudo, considerando os dados da Afubra, é possível estimar que há 21.688 propriedades que cultivam tabaco, representando $66,38 \%$ do total de propriedades de toda a Bacia Hidrográfica, em que o tamanho médio destas propriedades é de 20,40 ha.

Portanto, é possível perceber que a região tem enorme potencial para desenvolver a atividade florestal de forma plena. Há demanda por commodities, como a lenha e a matéria-prima para indústria de placas e celulose, demanda por produtos para indústria de transformação, serrarias, em escala menor produtos não madeiráveis, como a erva-mate, e de forma bastante incipiente, a agroindústria do palmito.

Além disso, a região tem uma produção razoável de mudas, que atende à procura. Isto posto, não é difícil concluir que os principais atores para a implementação de uma cadeia produtiva florestal estão na região. Por isso e pelos dados obtidos, conclui-se que a região tem vocação para atividade florestal, tanto pelas questões culturais, econômicas, climáticas e de solo.

\section{Diagnóstico da atividade florestal}

A análise da atividade florestal ou do seu potencial é, muitas vezes, reduzida a produção de madeira simplesmente, sendo desconsiderada a potencialidade de outras funções que a floresta, ou o ecossistema florestal desempenha.

Como exemplo destas distintas oportunidades tem-se a utilização da floresta como reguladora do clima, atenuadora dos efeitos do aquecimento global e garantia perene de fornecimento de água aos nossos mananciais que, por sua vez, resultam em segurança para a sociedade, como fornecedora de água para população, agricultura, pecuária e garantia de volume de água suficiente para manutenção do potencial hidroelétrico do país.

A atividade florestal no Vale do Rio Pardo tem se caracterizado como fornecedora de lenha. Além disso, a ideia recorrente de que o melhor investimento em florestas é para produção de lenha e, recentemente, a pressão igualmente enorme sobre as florestas de eucaliptos, pelas serrarias dedicadas à produção de pallets, não tem permitido que florestas de eucalipto alcancem rotações mais longas.

Especificamente no RS, a fumicultura mantém um consumo médio na década de 1970, de 2.600.000 $\mathrm{m}^{\text {st }}$ de lenha, e, na virada do século XX, o RS consumia $3.000 .000 \mathrm{~m}^{\text {st }}$. Para fazer a transformação para $\mathrm{m}^{3}$, utiliza-se um fator de 0,73 que, segundo Barros (2006), é o mais indicado, chega-se ao volume médio de $2.100 .000 \mathrm{~m}^{3}$.

\section{Cobertura florestal}

Os dados fornecidos pela Afubra apontam para corroborar o que as diferentes pesquisas e levantamentos já constataram. Os dados da Tabela 4 ilustram que as propriedades da região em estudo têm $14,96 \%$, em média, de sua área coberta com florestas naturais em diferentes estágios sucessionais. Estas mesmas propriedades apresentam uma área com florestas plantadas de 7,68\%, em média. Com estes dados é interessante observar que as áreas com cobertura florestal nativa aumentam com o aumento da área total das propriedades.

Todavia, pode-se afirmar que a área de florestamento, independentemente do tamanho da propriedade, se mantém simétrica, tendo uma tendência de ser maior nas pequenas áreas e diminuindo a sua participação com o aumento da propriedade. Uma possível explicação para isso é o fato do consumo de lenha ser semelhante em todas as classes de propriedade, o que acaba resultando em uma participação maior nas classes menores, e, também, a falta de visão para investir em florestamento para além da necessidade do consumo próprio.

\section{Consumo de lenha}

A Tabela 5 traz dados em relação ao tamanho da propriedade e o perfil de consumo de lenha, próprio ou de terceiros, e fica evidente que as micropropriedades, abaixo de 10 ha, praticamente a totalidade da lenha que consomem é adquirida de terceiros, representando $67,43 \%$ do total de lenha consumido e 
$78,86 \%$ do total da lenha adquirida.

$\mathrm{Na}$ Tabela 5, observa-se que a classe de produtores não proprietários, apresenta consumo de lenha própria. Isto certamente ocorre porque o proprietário que cede a área para o plantio também permite que seja utilizada a lenha disponível na propriedade.

Também, é possível observar que, a partir da Classe 3, a lenha própria tem uma participação superior em relação à lenha comprada. Porém, ao considerar a área total da propriedade, parece não ser lógico ter área disponível para o cultivo de florestas, não utilizá-la e ainda adquirir lenha de terceiros.

A manutenção de estoques de florestas, nas propriedades com área disponível, é fundamental para viabilizar os produtores das Classes 1 e 2, uma vez que a disponibilidade de madeira na região manteria os preços estabilizados, permitindo a viabilidade econômica destas classes de produtores. Da mesma forma, é importante criar mecanismos que estimulem os proprietários com maior disponibilidade de terra, para que aumentem sua área com florestas, diminuindo sua dependência da compra e possibilitando uma maior disponibilidade regional de lenha e, consequentemente, oportunidade de comercialização de outros produtos florestais.

TABELA 4: Cobertura florestal nas propriedades dos fumicultores na Bacia do Rio Pardo.

TABLE 4: Forest covering in the properties of tobacco growers in the basin of 'Pardo' river.

\begin{tabular}{cccc}
\hline $\begin{array}{c}\text { Classe de } \\
\text { tamanho (ha) }\end{array}$ & Cobertura arbórea nativa (\%) & Cobertura arbórea florestada (\%) & Total (\%) \\
\hline Arrendatários & 0,0 & 0,0 & \\
00,1 a 10,0 & 8,3 & 11,1 & 19,4 \\
10,1 a 15,0 & 14,1 & 11,4 & 25,5 \\
15,1 a 20,0 & 17,7 & 9,8 & 27,5 \\
20,1 a 30,0 & 19,5 & 8,9 & 28,4 \\
30,1 a 40,0 & 20,1 & 8,4 & 28,5 \\
40,1 a 50,0 & 22,0 & 6,7 & 28,7 \\
$>50,1$ & 18,0 & 5,2 & 23,2 \\
\hline Média & 17,1 & 8,8 & \\
\hline
\end{tabular}

Fonte: Afubra (2008).

TABELA 5: Consumo de lenha nas propriedades dos fumicultores na Bacia do Rio Pardo, na safra 2007/2008. TABLE 5: Consumption of firewood in properties of tobacco growers in 'Pardo' river basin, in the harvest 2007/2008.

\begin{tabular}{ccccccc}
\hline Classe & Tamanho (ha) & $\begin{array}{c}\text { Consumo de } \\
\text { lenha } \\
\text { própria }\left(\mathrm{m}^{\text {st }}\right)\end{array}$ & $\begin{array}{c}\text { Participação } \\
(\%)\end{array}$ & $\begin{array}{c}\text { Consumo de } \\
\text { lenha } \\
\text { comprada }\left(\mathrm{m}^{\text {st }}\right)\end{array}$ & $\begin{array}{c}\text { Participação } \\
(\%)\end{array}$ & $\begin{array}{c}\text { Consumo total de } \\
\text { lenha }\left(\mathrm{m}^{\mathrm{st}}\right)\end{array}$ \\
\hline 1 & Arrendatário & 96.507 & 8,9 & 284.454 & 26,3 & 380.961 \\
2 & 00,1 a 10,0 & 108.832 & 10,1 & 238.576 & 22,1 & 347.408 \\
3 & 10,1 a 15,0 & 72.248 & 6,7 & 62.460 & 5,8 & 134.708 \\
4 & 15,1 a 20,0 & 51.943 & 4,8 & 30.845 & 2,9 & 82.788 \\
5 & 20,1 a 30,0 & 48.933 & 4,5 & 26.255 & 2,4 & 75.188 \\
6 & 30,1 a 40,0 & 18.217 & 1,7 & 10.433 & 1,0 & 28.650 \\
7 & 40,1 a 50,0 & 8.741 & 0,8 & 4.088 & 0,4 & 12.829 \\
8 & $>50,1$ & 11.540 & 1,1 & 6.072 & 0,6 & 17.612 \\
\hline & Total & 416.961 & 38,6 & 663.183 & 61,4 & 1.080 .144 \\
\hline
\end{tabular}




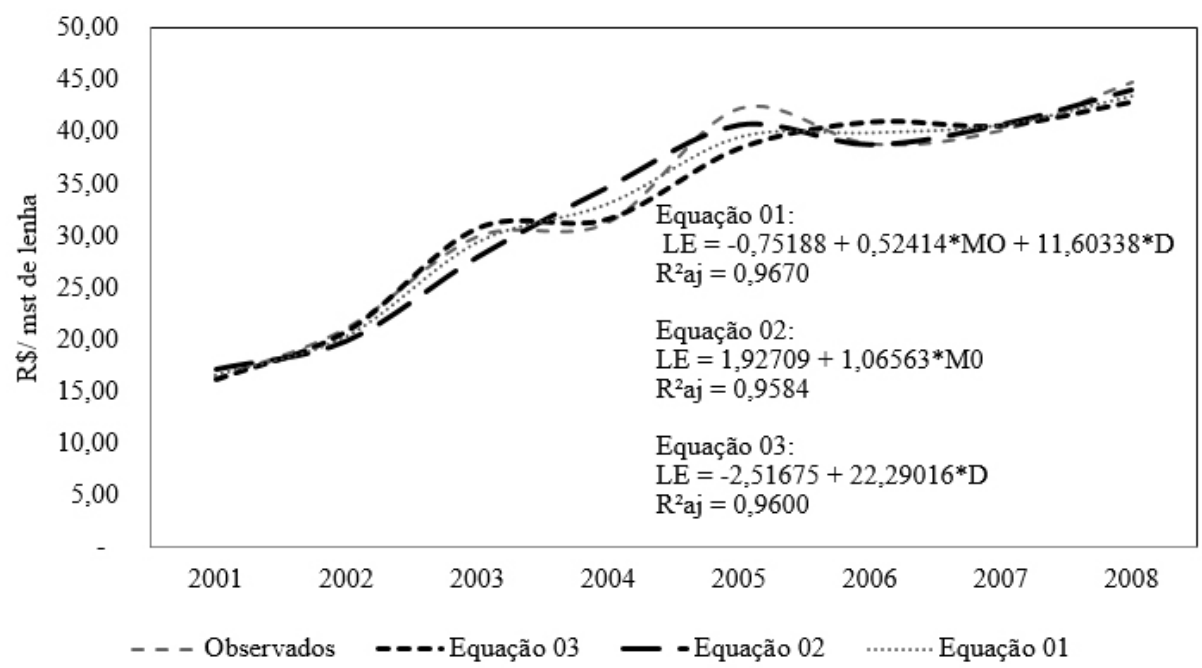

FIGURA 1: Série histórica do preço da lenha observada e ajustada tendo como variáveis a mão de obra (MO) e o óleo diesel (D).

FIGURE 1: Historical series of the price of observed and adjusted firewood having as variables the workforce (MO) and the oil diesel (D).

A lenha é um insumo fundamental no processo de produção do tabaco e sua participação no custo de produção, na safra 2008/2009, foi de $8,8 \%$, conforme dados disponibilizados pela Afubra. Nos últimos 20 anos, a média situa-se em $9,43 \%$, apresentando um indicativo de queda e se estabilizando na faixa de $8 \%$. A redução da participação da lenha no custo está diretamente associada ao trabalho de fomento florestal realizado pelo setor, que conseguiu expandir a base florestal, sem diminuir a área de produção agrícola e de pecuária.

A lenha tem uma forte correlação com o valor da mão de obra e com o valor do óleo diesel. $\mathrm{Na}$ Figura 1 foram construídas algumas equações que projetam o preço da lenha em função das variáveis: valor da mão de obra e do valor do litro do óleo diesel.

O custo de produção de tabaco é de R $\$ 10.297,00 /$ ha, considerando a participação da lenha na safra de 2008/09 de 8,8\%, tem-se que a despesa com lenha para 1 ha de tabaco é de $\mathrm{R} \$ 906,14$, valor que supera a totalidade dos insumos necessários para plantar 1 hectare com Eucalyptus spp.

Considerando que uma família planta em média 1,83 ha de tabaco, a sua despesa anual com o insumo lenha será da ordem de $\mathrm{R} \$ 1.658,37$, com este valor permite não só adquirir os insumos necessários para o plantio de 1 ha de Eucalyptus spp., bem como pagar também os serviços de plantio e de manutenção da floresta plantada.

\section{Inventário florestal}

O inventário florestal, realizado em 130 propriedades, resultou um número de 1.191 parcelas amostrais. Na Figura 2 verifica-se que este número de unidades amostrais, foi suficiente, uma vez que este número de propriedades permitiu uma estabilização do coeficiente de variação, sem alterações significativas.

A realização deste inventário florestal foi importante, porque, no que se tem observado em publicações e relatórios da área fumageira, há uma situação bastante confortável em relação ao estoque de áreas de florestas e de volume de madeira, disponível para energia, no caso da lenha para a cura das folhas de tabaco.

Porém, ao se analisarem os dados da Tabela 6, verifica-se que há realmente uma significativa área com florestas, mas com sérias deficiências produtivas e tecnológicas. Ao se observar o espaço vital na ocasião do plantio, nota-se que a opção é por reduzidos espaçamentos, o que resulta em um elevado percentual de falhas, independentemente da classe de tamanho das propriedades. 


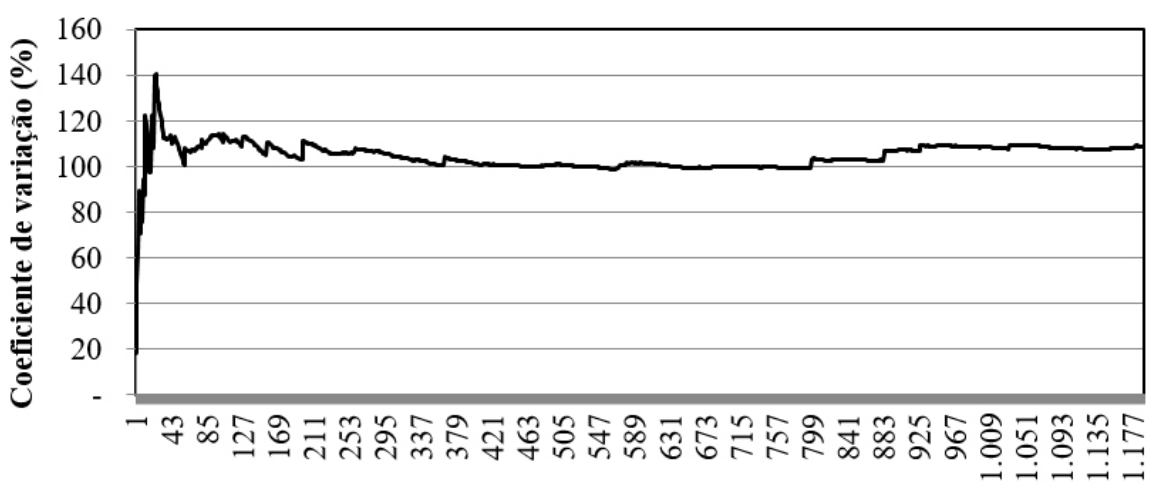

Número de unidades amostrais

FIGURA 2: Coeficiente de variação das unidades amostrais, para volume/ha.

FIGURE 2: Coefficient of variation of the sample units, for volume/ha.

TABELA 6: Perfil do estoque de florestas nas propriedades dos fumicultores da Bacia do Rio Pardo. TABLE 6: Profile of the supply of forests in properties of tobacco growers of the basin of 'Pardo' river.

\begin{tabular}{ccccccc}
\hline $\begin{array}{c}\text { Tamanho das } \\
\text { propriedades } \\
\text { (ha) }\end{array}$ & $\begin{array}{c}\text { Idade } \\
\text { (Anos) })\end{array}$ & $\begin{array}{c}\text { DAP } \\
(\mathrm{cm})\end{array}$ & Volume $\left(\mathrm{m}^{3} / \mathrm{ha}\right)$ & $\begin{array}{c}\text { Número de árvores/ } \\
\text { ha existentes }\end{array}$ & $\begin{array}{c}\text { Falhas } \\
\text { Estimadas } \\
(\%)\end{array}$ & $\begin{array}{c}\text { Espaço vital } \\
\text { médio no } \\
\text { plantio }\left(\mathrm{m}^{2}\right)\end{array}$ \\
\hline$<10$ & 7,3 & 14,9 & 350,82 & 1837 & 65 & 1,94 \\
10,1 a 15,0 & 7,8 & 16,4 & 427,04 & 1629 & 64 & 2,24 \\
15,1 a 20,0 & 5,8 & 14,4 & 307,95 & 1672 & 65 & 2,16 \\
20,1 a 30,0 & 7,7 & 15,6 & 405,11 & 1835 & 66 & 1,99 \\
30,1 a 40,0 & 10,6 & 16,0 & 308,20 & 1675 & 67 & 2,17 \\
40,1 a 50,0 & 6,2 & 14,2 & 246,95 & 1676 & 54 & 3,04 \\
$>50$ & 11,5 & 19,2 & 370,79 & 1349 & 70 & 2,31 \\
\hline
\end{tabular}

Em estudo de espaçamento para Eucalyptus saligna, Guimarães (1961), utilizando dimensões com variação de $1,0 \times 1,0 \mathrm{~m}$ até 3,0 × 2,0 m, constatou que o número de árvores eliminadas pela concorrência aumentava com a densidade dos povoamentos, tendo sido maior nos povoamentos de menor espaçamento. Observou, ainda, que a sobrevivência, aos 8 anos de idade, foi influenciada pelo espaçamento. Nos espaçamentos inferiores a $2 \mathrm{~m}^{2} /$ planta, a sobrevivência foi da ordem de $38 \%$ e nos maiores que $4,5 \mathrm{~m}^{2} /$ planta foi de aproximadamente $56 \%$.

Mesmo que o volume por hectare seja razoável, ao se analisarem os diâmetros médios percebe-se que estão abaixo do que é possível se obter com o gênero Eucalyptus Sobre isto, Berger (2000), estudando clones de Eucalyptus saligna, concluiu que há uma tendência significativa de aumento do diâmetro médio com o aumento do espaçamento, tendo encontrado um diâmetro médio de $23,2 \mathrm{~cm}$ aos 10,5 anos, com espaço médio por planta de $9 \mathrm{~m}^{2}$, enquanto no inventário foi observado um diâmetro médio de $16,0 \mathrm{~cm}$ na mesma idade, em um espaço vital de $2,17 \mathrm{~m}^{2}$ por planta.

Schneider et al. (2004) estudando a influência do espaçamento no crescimento em diâmetro de Eucalyptus grandis, em Rio Pardo, concluíram que o diâmetro é fortemente afetado pela densidade populacional, sendo que, o diâmetro médio estimado foi diretamente proporcional à grandeza do espaçamento, sendo maior nos espaçamentos mais amplos do que nos mais reduzidos. Os autores encontraram diâmetros semelhantes ao do inventário do presente estudo, tendo encontrado em um espaçamento de $2 \mathrm{~m}^{2}$, um diâmetro médio de $14,9 \mathrm{~cm}$ aos 11 anos.

A implicação deste modelo é a restrição de possibilidades de uso da floresta, como também do 
elevado custo por $\mathrm{m}^{3}$ produzido. Além disso, os espaçamentos apertados limitam o sortimento das florestas, influenciando as taxas de crescimento, a qualidade da madeira produzida, a idade de corte, os desbastes, as práticas de manejo e, consequentemente, os custos de produção, sendo provavelmente, uma das principais técnicas de manejo que visa à qualidade e à produtividade da matéria-prima (SILVA et al., 2003).

O fundamental desta análise é o fato de que, ao não se dar a devida atenção aos programas de fomento florestal, subestima-se o potencial florestal nas pequenas propriedades.

Isto porque, o produtor rural acha natural que a sua floresta tenha estas características, e os agentes fomentadores (públicos, privados ou associativos), nunca the mostraram um diferencial, para utilizar "modelos" de plantações florestais corretos. A Tabela 7 mostra o desperdício de recursos de pequenos agricultores que, ao ter uma pequena área de terra, também disponibilizam uma pequena área da sua propriedade para florestas plantadas. Nesta pequena floresta depositam todas as suas esperanças em uma "aposentadoria verde", muito propalada pelos programas de fomento florestal.

Considerando os dados da Tabela 7, chega a ser surrealista realizar um programa de fomento florestal, cujo índice de eficiência é de 34,36\%. Por analogia seria como plantar 3 mudas para colher apenas uma árvore.

Este reflexo é fundamentalmente da falta de assistência técnica e da utilização de um referencial equivocado, ou seja, de que o importante é distribuir mudas para os produtores não importando qual o resultado.

Isto é comprovado pelos dados que as indústrias do tabaco divulgam, sempre fazendo referência ao número de mudas fomentadas e não ao volume de lenha disponível nas propriedades.

Na Tabela 5 encontram-se os dados do volume total de lenha consumida na área do estudo: 1.080 .144 $\mathrm{m}^{\text {st }}$, o que corresponde a $788.505 \mathrm{~m}^{3}$, considerando que o IMA obtido no inventário florestal foi de $42,39 \mathrm{~m}^{3} /$ ha/ano, conclui-se que é necessária uma área florestal de 18.601 ha para suprir este consumo.

$\mathrm{Na}$ Tabela 4, encontra-se o índice de área de florestamento, na ordem de 8,8\%, sabendo-se que as propriedades rurais, na área de estudo, têm 159.852 ha, é possível estimar a área de reflorestamento em 14.019 ha. Portanto, a partir destes dados, há na região um deficit de 4.582 ha, para que a região possa ser autossustentável em relação ao fornecimento de lenha.

Ainda, ao se considerar que a produção média das florestas, na área de estudo, é de $345,26 \mathrm{~m}^{3}$, e que a área com florestas é de 14.019 ha, é possível concluir que o estoque existente resulta em $4.840 .223 \mathrm{~m}^{3}$, satisfazendo a necessidade de abastecimento dos fornos para o equivalente a 6,14 safras de tabaco.

Diante deste quadro, há que se preocupar com a possibilidade de se buscar nas florestas nativas remanescentes, o suprimento necessário de lenha.

Mas, não é isso que os dados de campo mostram, uma vez que no inventário florestal, constatouse que apenas $1,56 \%$ do total de lenha consumida é proveniente de florestas naturais. Portanto, fica

TABELA 7: Comparação entre as florestas plantadas e as existentes obtidas no inventário florestal.

TABLE 7: Comparison between the planted forests and the existing ones obtained in the forest inventory.

\begin{tabular}{|c|c|c|c|}
\hline Classe de tamanho (ha) & $\mathrm{N}^{\mathrm{o}}$ de mudas plantadas ${ }^{1}$ & Existentes & Diferença \\
\hline$<10$ & 129.300 & 45.255 & -84.045 \\
\hline 10,1 a 15,0 & 188.800 & 67.968 & -120.832 \\
\hline 15,1 a 20,0 & 96.000 & 33.600 & -62.400 \\
\hline 20,1 a 30,0 & 241.500 & 82.110 & -159.390 \\
\hline 30,1 a 40,0 & 62.000 & 20.460 & -041.540 \\
\hline 40,1 a 50,0 & 43.000 & 19.780 & -23.220 \\
\hline$>50$ & 179.000 & 53.700 & -125.300 \\
\hline Total & 939.600 & 322.873 & -616.727 \\
\hline
\end{tabular}

Em que: Afubra (2008). 
demonstrado que o nível de consciência dos produtores, bem como o receio das elevadas multas, e os compromissos assumidos pelo setor descartam esta possibilidade. A alternativa que se apresenta é buscar fora destes municípios o volume de lenha necessária, o que tem representado uma evasão de recursos econômicos anuais na ordem de R\$33.366.930,00. Por outro lado, estes valores poderiam ser utilizados para expansão da atividade florestal na região, com grande repercussão social e econômica.

\section{Cenário atual e perspectivas}

Fica evidente a importância da atividade florestal na fumicultura, tanto pela importância que representa como insumo, para a secagem das folhas de tabaco, e consequentemente, uma redução no custo, bem como, pela oportunidade de uso múltiplo destas florestas para outros fins, além dos energéticos, tanto para manutenção da propriedade como para a geração de renda.

Portanto, ao desenvolver o tema do potencial da atividade florestal no contexto da agricultura familiar, mais especificamente nas famílias que plantam tabaco, a primeira opção é considerar a capacidade de uso múltiplo das florestas plantadas já existentes nestas propriedades e todos os atores envolvidos, públicos e privados.

$\mathrm{Na}$ área em estudo foi verificado um consumo anual de $1.080 .144 \mathrm{~m}^{\text {st }}$ de lenha (Tabela 5), correspondendo a 788.505,12 $\mathrm{m}^{3}$. Através dos dados da Tabela 6 , é possível constatar uma produção média de $345,26 \mathrm{~m}^{3} / \mathrm{ha}$, com um IMA na ordem de $42,39 \mathrm{~m}^{3} / \mathrm{ha} /$ ano. Isto permite concluir que o consumo de lenha, para ser sustentável, necessita de uma área de 18.601,0 ha.

Com a informação de que a área de florestas plantadas ainda não é suficiente para tornar a fumicultura do Vale do Rio Pardo autossuficiente em lenha, havendo um deficit na ordem de 4.582,0 ha, o que corresponde a $24,6 \%$, como explicar que $61,4 \%$ da lenha é adquirida de terceiros. A resposta para esta questão está no fato de que $78,9 \%$ de toda a lenha adquirida é realizado pelas classes 1 e 2 , ou seja, os que não têm terra e os que têm até 10 ha de área. Porém, os dados coletados pela Afubra que deram subsídios para a discussão anterior, são baseados na informação que o produtor forneceu a relação do número de árvores existentes. Para a Afubra chegar ao cálculo da área ocupada por estes florestamentos foi estimada uma média de 2.330 plantas por hectare, o que estabelece um espaço vital de $4,29 \mathrm{~m}^{2}$. Os dados encontrados pelo inventário florestal, apresentados na Tabela 6, apresentam um espaço vital médio de 2,26 $\mathrm{m}^{2} /$ planta e, com isso, modifica-se totalmente a situação florestal da fumicultura, conforme dados na Tabela 8.

Então, verifica-se que a área de florestas plantadas é de 8.055 ha, o que significa dizer que simplesmente não existem 7.241 ha, uma diferença de 52,7\% em relação ao valor apresentado pelo setor de tabaco. Com isso, é possível explicar também o volume de lenha adquirida pelos agricultores. Conclui-se que há urgência de estabelecer um plantio que ocupe uma área de 10.546 ha, para cobrir este deficit de área

TABELA 8: Situação real dos estoques de florestas plantadas.

TABLE 8: Real situation of the supplies of planted forests.

\begin{tabular}{cccccc}
\hline Classes & $\begin{array}{c}\text { Classe de } \\
\text { Tamanho (ha) }\end{array}$ & $\begin{array}{c}\text { Área Florestada } \\
\text { Estimada }\end{array}$ & $(\%)$ & $\begin{array}{c}\text { Área Florestada } \\
\text { Existente }\end{array}$ & $(\%)$ \\
\hline 1 & Sem Terra & & 0,0 & & 0,0 \\
2 & 00,1 a 10,0 & 4.367 & 11,9 & 2.300 & 5,8 \\
3 & 10,1 a 15,0 & 3.425 & 11,4 & 1.804 & 6,0 \\
4 & 15,1 a 20,0 & 2.454 & 9,8 & 1.292 & 5,2 \\
5 & 20,1 a 30,0 & 2.688 & 8,9 & 1.415 & 4,7 \\
6 & 30,1 a 40,0 & 1.158 & 8,4 & 610 & 4,4 \\
7 & 40,1 a 50,0 & 455 & 6,7 & 240 & 3,5 \\
8 & $>50,1$ & 749 & 5,2 & 394 & 2,7 \\
\hline & Médias & 8,9 & & 4,6 \\
\hline
\end{tabular}


TABELA 9: Volume de recursos necessários para suprir o deficit florestal de 10.546 ha, com espaço vital de $6 \mathrm{~m}^{2} /$ planta.

TABLE 9: Volume of necessary resources to supply the forest deficit of 10.546 ha, with vital space of 6 $\mathrm{m}^{2} /$ plant.

\begin{tabular}{lccc}
\hline \multicolumn{1}{c}{ Insumo } & Quantidade (un) & Valor Unitário (R\$) & Valor Total (R\$) \\
\hline Mudas de Eucalipto (muda) & 17.928 .200 & 0,18 & 3.227 .076 \\
Formicida (kg) & 31.638 & 9,35 & 295.815 \\
Fertilizantes (sc) & 35.856 & 83,00 & 2.976 .081 \\
Herbicidas (1) & 39.548 & 27,00 & 1.067 .782 \\
Mão de obra & 10.546 & 700.00 & 7.382 .200 \\
Preparo de solo & 10.546 & 250,00 & 2.636 .500 \\
\hline \multicolumn{1}{c}{ Total } & & $1.667,50$ & 17.585 .455 \\
\hline
\end{tabular}

de florestas plantadas.

Além disso, os estoques existentes ficam muito abaixo dos valores correntes, ou seja, para uma área florestal de 8.055 ha, com uma produção média de $345,26 \mathrm{~m}^{3} / \mathrm{ha}$, os estoques atuais são de $2.781 .069 \mathrm{~m}^{3}$, o que garante um abastecimento para apenas 3,5 anos.

Considerando que a lenha tem um custo médio de $\mathrm{R} \$ 44,78 / \mathrm{m}^{\text {st }}$, a região tem um balanço deficitário na ordem de R $\$ 29.697 .334,74$ ao ano, valor superior ao orçamento de 8 municípios da área em estudo e $6,39 \%$ do orçamento de todos os municípios.

Na Tabela 9, encontram-se os valores necessários para investir na autossuficiência do setor.

Observa-se que será necessário um valor total de R\$ 17.585.455,00, de investimentos em florestamentos para suprir o consumo regional. Este recurso poderia ser alocado anualmente, durante 7 anos (rotação em talhadia). Portanto, o valor de investimento seria de R \$2.512.207,00 por ano. Isto corresponderia a um plantio de 1.507,0 ha por ano. Então, aplicando-se este valor aos 13 municípios envolvidos nesta análise, chega-se a uma área de 116,0 ha/ano/município, com um valor de investimento anual, por município de R\$ 193.247,00. Assim, do ponto de vista quantitativo, é perfeitamente possível suprir o deficit de florestamento e, pelo volume de recursos e área necessários, fica evidente que o maior obstáculo é a interação entre todos os atores desta cadeia produtiva, uma vez que os recursos estão disponíveis através de diferentes programas, especialmente os relacionados ao PRONAF, como também é possível implementar as ações de extensão e assistência técnica, através de uma articulação mais proativa entre todos os atores desta cadeia produtiva.

Com estes resultados também se evidencia a necessidade de adoção de técnicas de extensão rural para modificar o quadro que se apresenta nos florestamentos da região, de maneira que os produtores rurais possam perceber a necessidade de adoção das melhores técnicas, o que permitirá, além de maximizar o uso do solo, que via de regra é pequeno, uma maior produção florestal.

As informações encontradas no estudo abrem perspectivas para continuidade da pesquisa visando buscar subsídios para traçar ações de longo prazo, voltadas à análise das ações de extensão e fomento florestal, e de disponibilidade de matéria-prima para definir políticas de ampliação de investimentos em projetos florestais. Isto pode ser executado mediante a instalação de parcelas amostrais permanentes, tornando possível coletar dados anuais e construir, com estes dados, curvas e estimativas de crescimento e produção florestal.

\section{CONCLUSÕES}

As florestas plantadas na Bacia Hidrográfica do Rio Pardo apresentam carências que foram evidenciadas pela alta porcentagem de falhas e reduzido espaçamento de plantio. Ficou caracterizado um problema de política pública, já que a maioria dos agricultores é composta de pequenos proprietários rurais familiares que não recebem uma adequada assistência técnica florestal, que influencia diretamente no 
insucesso dos florestamentos.

Conforme foi constatado no estudo no ano de 2008, baseado no incremento médio e área de florestas, conclui-se que a base florestal da região não é suficiente para atender ao consumo dos produtores, sendo que a maior parte da lenha utilizada é comprada de terceiros. Somente com o florestamento nas áreas atualmente mantidas em descanso nas propriedades, seria possível atingir a plena sustentabilidade em relação ao fornecimento de lenha, sendo que o volume de recursos necessários seria inferior à atual evasão regional de recursos devido à aquisição da lenha.

\section{REFERÊNCIAS}

ANDRAE, F. H. Ecologia florestal. Santa Maria: UFSM, 1978. 250 p.

BARROS, M. V. Fator de cubicação para madeira empilhada de Eucalyptus grandis W. Hill ex Maden, com toretes de dois comprimentos, e sua variação com o tempo de exposição no ambiente. 2006. 103 p. Dissertação (Mestrado em Engenharia Florestal) - Universidade Federal de Santa Maria, Santa Maria, 2006.

BERGER, R. Crescimento e qualidade da madeira de um clone de Eucalyptus saligna Smith sob o efeito do espaçamento e da fertilização. 2000. 126 p. Dissertação (Mestrado em Engenharia Florestal) - Universidade Federal de Santa Maria, Santa Maria, 2000.

ETGES, V. E. Sujeição e resistência: os camponeses gaúchos e a indústria do fumo. Porto Alegre: FEE, 1989.

ETGES, V. E. A região no contexto da golabização: o caso do Vale do Rio Pardo. In: VOGT, O. P.; SILVEIRA, R. L. (Org.). Vale do Rio pardo: (re)conhecendo a região. Santa Cruz do Sul: Edunisc, 2001, p. 351-366.

FARIAS, J. A.; BIANCO, S. Reflorestamento: bom para o meio ambiente e para sua propriedade. Rio de Janeiro: Souza Cruz, 1999.

FERREIRA. C. A.; GALVÃO, A. P. M. Importância da atividade florestal no Brasil. In: GALVÃO, A. P. M. (Org.). Reflorestamento de propriedades rurais para fins produtivos e ambientais: um guia para ações municipais e regionais. Brasília: Embrapa Comunicação para Transferência de Tecnologia; Colombo: Embrapa Florestas, 2000. 351p.

FREY, M. R.; WITTMANN, M. L. Práticas de fomento florestal e incentivo à preservação das matas nativas na fumicultura. Redes, Santa Cruz do Sul, v. 12, n. 3, p. 99-117, 2007.

GOETZE, M.; THOMÉ, G. C. H. Efeito alelopático de extratos de Nicotiana tabacum e Eucalyptus grandis sobre a germinação de três espécies de hortaliças. R. Brasileira de Agrociência, Pelotas, v. 10, n. 1, p. 43-50, 2004.

GUIMARÃES, R. F. Ensaio de espaçamento em Eucalyptus saligna Sm. para produção de lenha. Serv. Flor. CIA Paulista Estrada Ferro Boi., 6. ed. 1961. 42 p.

IBDF - Instituto Brasileiro de Desenvolvimento Florestal. Inventário florestal nacional - reflorestamento Rio Grande do Sul. Brasília: IBDF, 1983. 182 p.

MÜLLER, I. Avaliação da produtividade da Acacia mearnsii De Wild. (Acácia negra) em função de diferentes espaçamentos. 2006. 131 p. Dissertação (Mestrado em Engenharia de Produção) - Universidade Federal de Santa Maria, Santa Maria, 2006.

PELLICO NETO, S.; BRENA, D. A. Inventário florestal. Curitiba: UFPR. 1997. 316 p.

PELLICO NETTO, S. Amostragem em dois estágios com unidades primárias de tamanhos diferentes. Ciência Florestal, Santa Maria, v. 6, n. 1, p. 147-155, 1996.

SCHNEIDER, P. R. et al. Produção de madeira para energia de Eucalyptus grandis em diferentes espaçamentos na região de Rio Pardo, Rio Grande do Sul, Brasil. In: $3^{\circ}$ SIMPÓSIO LATINO-AMERICANO SOBRE MANEJO FLORESTAL, 2004, Santa Maria. Anais... Santa Maria: UFSM/CCR/PROGRAMA DE PÓS-GRADUAÇÃO EM ENG. FLORESTAL, 2004. p. 1-6.

SEMA - Secretaria Estadual do Meio Ambiente do RS. Inventário florestal contínuo. Porto Alegre: UFSM/SEMA - RS, 2003. Disponível em: <http://coralx.ufsm.br/ifcrs/frame.htm.> Acesso em 02 de agosto de 2009 
SILVA, H. D.; BELLOTE, A. F. J.; FERREIRA, C. A. Cultivo do eucalipto. Colombo: Embrapa Florestas, 2003.

SILVA, J. C. Eucalipto: desfazendo mitos e preconceitos. Revista da Madeira, Curitiba, 63. ed., p. 52-56, 2003.

TONIETTO, L.; STEIN, P. P. Silvicultura da Acácia negra (Acacia mearnsii De Wild.) no Brasil. Florestar Estatístico, São Paulo, v. 4, n. 12, p. 11-16, 1997.

VOGT, O. P. Produtor integrado: um apêndice da exploração industrial. In: Centro de Estudos Marxistas.

Os trabalhos e os dias: ensaios de interpretação marxista. Passo Fundo: UPF, 2000. p. 163-179 